\title{
Trace determination of airborne polyfluorinated iodine alkanes using multisorbent thermal desorption/gas chromatography/high resolution mass spectrometry
}

\author{
Ting Ruan, Yawei Wang, Qinghua Zhang, Lei Ding, Pu Wang, Guangbo Qu, \\ Chang Wang, Thanh Wang, Guibin Jiang* \\ State Key Laboratory of Environmental Chemistry and Ecotoxicology, Research Center for Eco-Environmental Sciences, Chinese Academy of Sciences, \\ P.O. Box 2871, Beijing, 100085, China
}

\section{A R T I C L E I N F O}

\section{Article history:}

Received 8 January 2010

Received in revised form 3 April 2010

Accepted 19 April 2010

Available online 24 April 2010

\section{Keywords:}

Polyfluorinated iodine alkanes

PFC

Telomer

Thermal desorption

Tenax

Gas chromatography/high resolution mass

spectrometry

\begin{abstract}
A B S T R A C T
A novel gas chromatography/high resolution mass spectrometry method coupled with multisorbent thermal desorption cartridges has been developed for the determination of volatile neutral polyfluorinated iodine alkanes (PFIs) in airborne samples. It allows, for the first time, simultaneous analysis of four mono-iodized perfluorinated alkanes, three diiodized perfluorinated alkanes and four mono-iodized polyfluorinated telomers in ambient air samples. 3.75 L air sample was passed through a sorbent tube packed with $150 \mathrm{mg}$ of Tenax TA and $200 \mathrm{mg}$ of Carbograph 1TD for analyte adsorption. Important factors during the analysis procedures, such as safe sampling volume, air sampling rate, analyte desorption and transfer strategies, were optimized and good thermal desorption efficiencies were obtained. The method detection limit (MDL) concentration ranged from $0.04 \mathrm{pg} / \mathrm{L}$ for $1 \mathrm{H}, 1 \mathrm{H}, 2 \mathrm{H}, 2 \mathrm{H}$-perfluorododecyl iodide to $1.2 \mathrm{pg} / \mathrm{L}$ for perfluorohexyl iodide, and instrument response of a seven-point calibration was linear in the range of $10-1000 \mathrm{pg}$. Travel spike recoveries ranged from $83 \%$ to $116 \%$. Small variabilities of less than $36 \%$ were obtained near the MDLs and the differences between triplicates were even smaller (2.1-7.3\%) at 200 pg spiked level. The method was successfully applied to analyze ambient air samples collected near a point source, and five PFIs were identified (10.8-85.0 pg/L), with none of the analytes detectable at the background site.
\end{abstract}

(C) 2010 Published by Elsevier B.V.

\section{Introduction}

Fluorinated additive materials have a wide range of applications such as in surfactants, lubricants, varnishes, pesticides and vinyl polymerization [1,2]. Regulatory efforts are underway to limit the use of some of these chemicals, mainly the perfluorinated compounds (PFCs), due to concerns over their environmental persistency, bioaccumulation ability and toxicity [3,4]. Among the PFCs, perfluorosulfonates (PFSAs) and perfluorocarboxylates (PFCAs) are most widely detected in human $[5,6]$ and other biological samples including those in pristine areas such as the Arctic [7,8]. Airborne fluorotelomer alcohols (FTOHs) have attracted considerable attention mainly due to their abilities for long range atmospheric transport $[9,10]$ and can act as volatile precursors that may undergo degradation to form PFCAs and other related compounds $[11,12]$.

\footnotetext{
* Corresponding author. Tel.: +8610 6284 9334; fax: +861062849179

E-mail address: gbjiang@rcees.ac.cn (G. Jiang).
}

Polyfluorinated iodine alkanes (PFIs) consist of an even numbered hydrophobic alkyl chain (typically $C_{4}-C_{12}$ ) which is fully or partially fluorinated and include an iodine atom at one or both of the ends (Table 1 ). They are reaction products synthesized from telomerization process by iodine pentafluoride reacting with unsaturated taxogen molecules such as tetrafluoroethylene and ethylene. PFIs are used as important industrial intermediates for the production of various PFCs, such as fluorotelomer alcohols, olefins and acrylate monomers [2,13]. Since the usage of electrochemical fluorination method has been terminated since 2002 in most countries, the telomerization process has been increasingly popular in the production of PFCs. The increase in production volume of PFIs might therefore be of particular concern as the risk subsequent release to the environment also increases [14,15]. They might possess abilities to undergo long range transport to remote areas such as the Arctic [16] and become potential precursors to form other known PFC contaminants [17] by e.g. nucleophilic attack on the iodine atom [18].

Martin et al. [19] were the first to use high volume active sampling to collect and quantify airborne FTOHs, N-alkyl perfluorooctane sulfonamides and sulfonamidoethanols by ana- 
Table 1

Analyte name, structure and other relevant data.

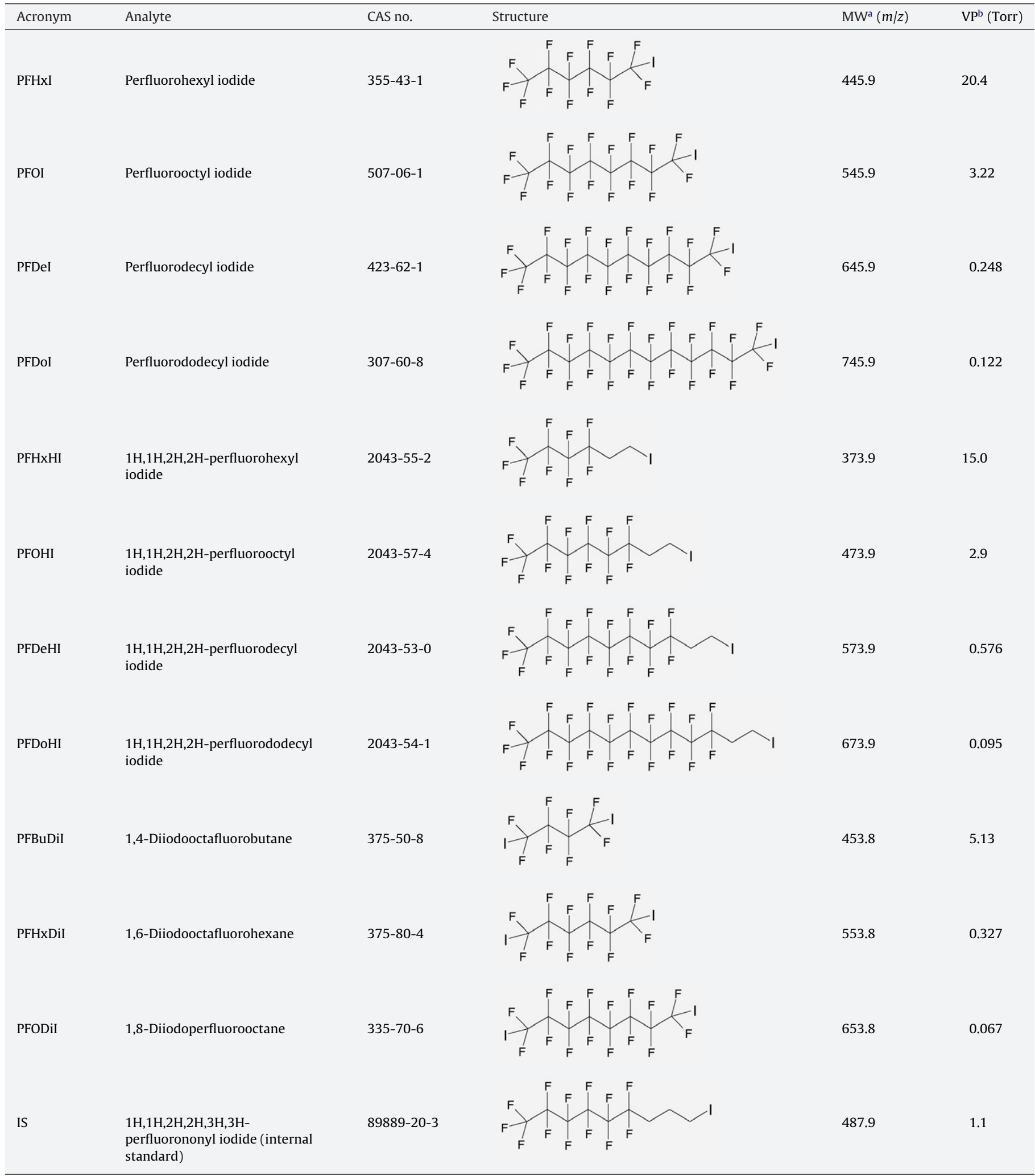

a Average molecular weight.

b Estimated vapor pressure calculated by USEPA EPI Suite V3.2. 
Table 2

HRMS Parameters for MID analysis in the EI mode.

\begin{tabular}{|c|c|c|c|c|c|c|}
\hline \multirow[t]{2}{*}{ Acronym } & \multicolumn{4}{|c|}{ Ions monitored $(m / z)^{a}$} & \multirow[t]{2}{*}{$\mathrm{Q} 1 / \mathrm{Q} 2^{\mathrm{b}}$ ratio } & \multirow[t]{2}{*}{$\mathrm{RT}^{\mathrm{c}}(\min )$} \\
\hline & Lock Mass & Cali Mass & Quan Ion & Qual Ion & & \\
\hline PFHxI & 313.983 & 413.977 & 318.9792 & 445.8837 & 10.9 & 7.54 \\
\hline PFOI & 413.977 & 501.971 & 418.9729 & 545.8773 & 13.8 & 12.63 \\
\hline PFDeI & 463.974 & 501.971 & 518.9665 & 480.9697 & 4.2 & 17.02 \\
\hline PFDoI & 575.967 & 613.964 & 618.9600 & 580.9650 & 1.7 & 20.82 \\
\hline PFHxHI & 313.983 & 413.977 & 373.9214 & N.C. ${ }^{d}$ & N.C. & 14.98 \\
\hline PFOHI & 313.983 & 463.974 & 473.9150 & 327.0043 & 1.5 & 19.39 \\
\hline PFDeHI & 425.977 & 501.971 & 573.9086 & 426.9979 & 1.5 & 23.21 \\
\hline PFDoHI & 501.971 & 613.964 & 673.9022 & 526.9915 & 1.7 & 26.61 \\
\hline PFBuDiI & 313.983 & 413.977 & 326.8917 & 453.7962 & 14.5 & 20.25 \\
\hline PFHxDiI & 425.977 & 501.971 & 426.8853 & 553.7898 & 15.8 & 24.39 \\
\hline PFODiI & 375.980 & 413.977 & 526.8789 & 380.9760 & 1.9 & 28.09 \\
\hline IS & 313.983 & 463.974 & 361.0262 & 487.9307 & 16.7 & 24.85 \\
\hline
\end{tabular}

a Lock/Cali Mass, fragment ions of FC43 used as equipment reference. Quan/Qual ions are separately of Quantification and Identification Use.

b Average ratio of Quan/Qual ion.

c Retention time.

d Not calculated, for background interference.

lyte enrichment on glass-fiber filters (for particle phase) and polyurethane foam/XAD-2 (for gas phase), followed by Soxhlet extraction and analyte preconcentration through rotary vaporization. Minor modifications of this solvent-based method have thereafter been widely used to investigate airborne concentrations of polyfluorinated substances in e.g. the Arctic atmosphere [20], USA [21], Asia [22], industrialized and remote areas in Central Europe and less urbanized regions in the Southern Hemisphere [9]. Similar passive air sampler comprising of XAD-4 adsorbent impregnated in PUF disk has also been developed [23]. However, analyte preconcentration process in these solvent-based methods might be inappropriate for sample pretreatment of polyfluorinated iodine alkanes because of their high vapor pressures (estimated to be from 0.07 Torr for 1, 6-diiodooctafluorohexane to 20.4 Torr for perfluorohexyliodide [24]) which results in low recoveries. To our knowledge, no previous quantitative method for environmentally relevant PFIs has been published, and only one gas chromatography low resolution mass spectrometry (GC-LRMS) method reported the determination of perfluorooctyl iodide (PFOI) residual in fluorotelomer raw materials [25] by dissolution into commercial perfluorinated solvent Vertrel ${ }^{\circledR}$ XF and direct injection into the GCLRMS. However, the method detection limit (MDL) of $0.7 \mu \mathrm{g} / \mathrm{g}$ for PFOI in that work is not sufficient for the detection and quantification of trace PFIs in environmental air samples. Moreover, many important perfluorinated iodine alkanes and telomer homologues were not included in the mentioned work, and thus a robust analytical method is still unavailable for this purpose.

Adsorption/thermal desorption method is generally recognized and widely used as an effective technique for the analysis of a wide range of hazardous air pollutants [26-30] that are classified as volatile organic compounds (VOCs) and usually have vapor pressures above 0.1 Torr [27]. Compared with typical solvent-based extraction and injection scenarios, thermal desorption method requires less pretreatment procedures, reduces mass loss before quantification and enhances detection sensitivity by whole sample injection into the analytical instrument.

Thus, the goal of this work was to develop and validate a sensitive method for the determination of airborne polyfluorinated iodine alkanes by thermal desorption with multisorbent tubes filled with Tenax TA and Carbograph 1TD. Four mono-iodized perfluorinated alkanes, three diiodized perfluorinated alkanes and four mono-iodized telomers were included and the separation and quantification was achieved by gas chromatography with electron ionization high resolution mass spectrometry. This method facilitates simultaneous analysis for some of these potential hazardous air pollutants and it is hoped to help in elucidating further knowledge on the fate and behaviors of these PFIs in the environment.

\section{Experimental}

\subsection{Reagents}

Analyte names, abbreviations and other related data are shown in Table 1. PFHxI, PFDeI, PFDoI, PFOHI, PFDeHI, and PFODiI were obtained from Aldrich (St. Louis, MO). PFOI, PFHxHI, PFDoHI and IS were from Fluka (St. Louis, MO). PFBuDiI and PFHxDil were purchased from Alfa Aesar (WardHill, MA). HPLC grade methanol and acetone were respectively obtained from Fisher Scientific (Hampton, $\mathrm{NH}$ ) and Dima technology Inc. (Richmond Hill, ON).

Stock solvents of $1000 \mathrm{mg} / \mathrm{mL}$ were prepared individually in acetone. All working standard mixtures were prepared by gradual dilution in methanol from stock solvents for method development.

\subsection{Sorbent cartridges}

Standard stainless steel sorbent cartridges ( $89 \mathrm{~mm}$ long, $6.4 \mathrm{~mm}$ o.d., Markes International) were chosen for the adsorption/thermal desorption analysis. Each cartridge was pre-packed with $150 \mathrm{mg}$ of Tenax TA (35/60 mesh) and $200 \mathrm{mg}$ of Carbograph 1TD (40/60 mesh) by the cartridge supplier. Tenax TA [31,32] is a porous polymer sorbent with weak adsorption strength and is suitable for analytes with volatilities ranging from $n-C_{7}$ to $n-C_{30}$ normal alkanes, while Carbograph 1TD is also a non-specific graphitized carbon black material which has a relatively stronger sorbent strength for analytes from $n-C_{5}$ to $n-C_{14}$. The multibed sorbents have hydrophobic characteristics and are suitable for sampling under full humid conditions and re-packing is not necessary even after 100 thermal cycles. The cartridges were packed as such that the Tenax TA was at the inlet side to the sampling system.

Each cartridge was pre-cleaned before use by baking two times for $30 \mathrm{~min}$ at $325^{\circ} \mathrm{C}$ using $50 \mathrm{~mL} / \mathrm{min}$ high purity He gas and then was sealed tight with 2-piece, $1 / 4$ inch brass screw caps with single PTFE ferrule which were pre-rinsed in acetone. Conditioned cartridges were stored inside an air-tight container under refrigeration at $4{ }^{\circ} \mathrm{C}$. Low diffusive sampling rate under such conditions prevents sorbent contamination during the storage and sampling period.

\subsection{Instrumentation}

A TRACE GC Ultra gas chromatograph/high resolution doublefocusing magnetic sector (DFS) mass spectrometry system 
(GC-HRMS, Thermo Fisher Scientific, Waltham, MA) was coupled with a UNITY series 2 (Markes International, Llantrisant, Wales, UK) thermal desorption (TD) instrument and the TD-GC-HRMS system was used for pretreatment optimization and sample analysis. The thermal desorption instrument was directly coupled with the GC column through a preheated transfer line and a quick seal column connector (Markes International). Chromatographic separation was carried out on an Agilent DB-624 GC column (6\% cyanopropyl-phenyl, 94\% dimethyl polysiloxane, $0.25 \mathrm{~mm}$ i.d., $30 \mathrm{~m}$ in length, $1.4 \mu \mathrm{m}$ film thickness, J\&W Scientific, Folsom, CA). Oven temperature programs employed were as follows: initial temperature at $35^{\circ} \mathrm{C}$ and held for $6 \mathrm{~min}$, ramp to $135^{\circ} \mathrm{C}$ at $5^{\circ} \mathrm{C} / \mathrm{min}$, and $2{ }^{\circ} \mathrm{C} / \mathrm{min}$ to $145^{\circ} \mathrm{C}$. Electron impact (EI) ionization mode was used and source temperature was held at $250^{\circ} \mathrm{C}$. Mass spectrometric resolution was tuned to about 800 ( $5 \%$ valley definition) for spectrum scanning and around 5000 for ion confirmation and quantitative analysis. Full-scan (100-700 amu) spectral data were collected at a rate of $1.13 \mathrm{scan} / \mathrm{s}$. Multiple ion detection (MID) mode helped increase sensitivity and was used in quantitative data acquisition. HRMS parameters for MID analysis are summarized in Table 2. Perfluorotributylamine (FC43) was used as the instrument reference to ensure mass scanning precision. Ionization source energy was optimized to attain high abundance of characteristic ions. A split/splitless injector was equipped with the GC-MS system for liquid standard injection. Splitless injector temperature was set at 180 , $200,220,250$ and $280^{\circ} \mathrm{C}$ to check whether possible analyte thermal degradation could influence the accuracy of analysis. TD equipment parameters, such as desorption temperature and gas flow rate, were also optimized and discussed in the following section to obtain good analyte desorption efficiency. MS data acquisition and processing was performed using Xcalibur 2.0 software from Thermo Fisher Scientific.

\subsection{Standard mixture loading and sorbent cartridge desorption}

Replicate loading of analytical standards into desorption tubes is essential for the equipment calibration and method validation. The analyte standard mixtures and internal standard (IS) were introduced into sample cartridges through a Calibration Solution Loading Rig (Markes International), which is composed of an injection port, a sorbent tube connection point and a carrier gas needle valve. The makeup gas flow was set to $30 \mathrm{~mL} / \mathrm{min}$ and $1 \mu \mathrm{L}$ of standard mixtures in methanol was injected into the cartridges through the injection port by a $10 \mu \mathrm{L}$ Hamilton syringe. The liquid vaporized in a high flow of makeup gas and analytes adsorbed onto the sorbent in the vapor phase. Methanol was chosen as the solvent for its weak retention characteristic on the sorbents, and 5 min of carrier gas flow $(150 \mathrm{~mL})$ was sufficient for eliminating the solvent while ensuring analytes of interest to be retained.

A standard "trap/quick release" two stage desorption strategy was used for the analysis. Prior to desorption, parts of trapped water and non-retention components from the air were removed by a two-step split purge procedure. Except for laboratory blanks [33], all samples, travel spikes, QA/QC blanks and laboratory check standards were prepurged for 1 min with $15 \mathrm{~mL} / \mathrm{min}$ high purity He gas at ambient temperature. The cartridges were then heated and the analytes were primarily desorbed and back-flushed using $30 \mathrm{~mL} / \mathrm{min}$ high purity He gas through a graphitized carbon cold trap (Markes International), which was air-cooled at $-10^{\circ} \mathrm{C}$ with continuous flow of high purity $\mathrm{N}_{2}$ gas. Desorption temperature was set as $200,250,280^{\circ} \mathrm{C}$ and optimized for complete analyte desorption. Once the analytes refocused onto the trap, another $1 \mathrm{~min}$ pretrap fire purge was used to reduce water interference into the GC column. Afterward, the cold trap was heated to $300^{\circ} \mathrm{C}$ within $5 \mathrm{~s}$ at maximum heating rate and held for $3 \mathrm{~min}$. Splitless mode was chosen and all the analytes were injected into the analytical
GC column through a 1.2-m-long, 0.25-mm-i.d. deactivated silica capillary. Good peak shapes were obtained at this stage even carrier gas was used at a low flow rate of $1 \mathrm{~mL} / \mathrm{min}$.

\subsection{Breakthrough test}

Safe sampling volume (SSV) is a vital parameter for accurate quantification of thermal desorption methods. As there are no relevant breakthrough volume studies for the analytes of interest, tests were carried out by connecting two conditioned multibed cartridges to one another using a piece of silicone tube. $10 \mathrm{ng}$ of each analytes and IS compounds mixture in $1 \mu \mathrm{L}$ methanol was injected into the inlet of the first cartridge. Non-contaminated laboratory air $\left(25^{\circ} \mathrm{C}, 55 \%\right.$ relative humidity $)$ at different volumes $(1.4-100 \mathrm{~L})$ was pumped through the cartridges at a flow rate of 150,200 , $300 \mathrm{~mL} / \mathrm{min}$ using a portable sampling pump. At the end of each sampling cycle, the two cartridges were analyzed individually.

\subsection{Method validation and $Q A / Q C$}

Procedures were carried out to validate the airborne trace PFI determination methodology. To test the MDL and establish a calibration curve, sorbent cartridges were spiked with $200 \mathrm{pg}$ internal standards and analyte standard mixtures in series (5-1000 pg for each of the analyte, and analyzed in order). Another desorption cycle was applied to these analyzed cartridges at each level to test the sorbents desorption efficiency. Method accuracy was measured by travel spike test ( $500 \mathrm{pg}$ level) and repeatability checked at spiked low (10 pg) and medium (200 pg) levels, each in triplicate. Additional cycles with empty tubes were performed to make sure that system residues were eliminated as much as possible and correctly subtracted.

The QA/QC utilized was similar to that previous reported with little modification [27]. In brief, lot blanks, trip blanks, field blanks, travel spikes, laboratory blanks, and laboratory check standards were conducted. After cartridges were conditioned and packed for sampling, two lot blanks were randomly chosen and analyzed to check potential residues remaining on the sorbents. Internal standard residue might be observed due to cold trap adsorption, however, the level was usually much lower than $0.5 \%$ of spiked level and all analytes of interest were below their limits of detection. Two preconditioned cartridges were chosen as field blanks and were taken to the field with the sampling tubes. These blanks were uncapped and exposed to the air in the passive diffusive mode at one sampling cycle, re-sealed and taken to the laboratory for analysis. Three trip blanks were employed at similar fashion as the field blanks expect that the caps of the cartridges were kept sealed during the whole sampling period. For travel spikes, $500 \mathrm{pg}$ of each analyte of interest were spiked onto three preconditioned cartridges, which were taken to the field, kept well sealed during the sampling time and analysis to check possible analytes mass loss during the transportation. Internal standard of $200 \mathrm{pg} 1 \mathrm{H}, 1 \mathrm{H}, 2 \mathrm{H}$, $2 \mathrm{H}, 3 \mathrm{H}, 3 \mathrm{H}$-perfluorononyl iodide was added into these blank and spike tubes just before analysis. For laboratory blanks, $200 \mathrm{pg}$ of internal standard was spiked and stored during the same storage period as well as the field samples, and analyzed to exclude possible contamination in the laboratory. One laboratory check standard with $200 \mathrm{pg}$ of each analytes plus IS was added to every batch of seven sample to confirm the GC-MS status. If more than $15 \%$ deviation was observed, a new calibration curve was performed.

For the positive identification of the analytes of interest, important confirmation criteria published elsewhere [29,34] was utilized for the analysis. Briefly, the retention time of analytes in real samples have to match that of the standards within $5 \mathrm{~s}$. Chemicals positively identified in real samples with signal-to-noise ratio $(\mathrm{S} / \mathrm{N})$ greater than 10:1. Besides, almost all of the identified peaks met 

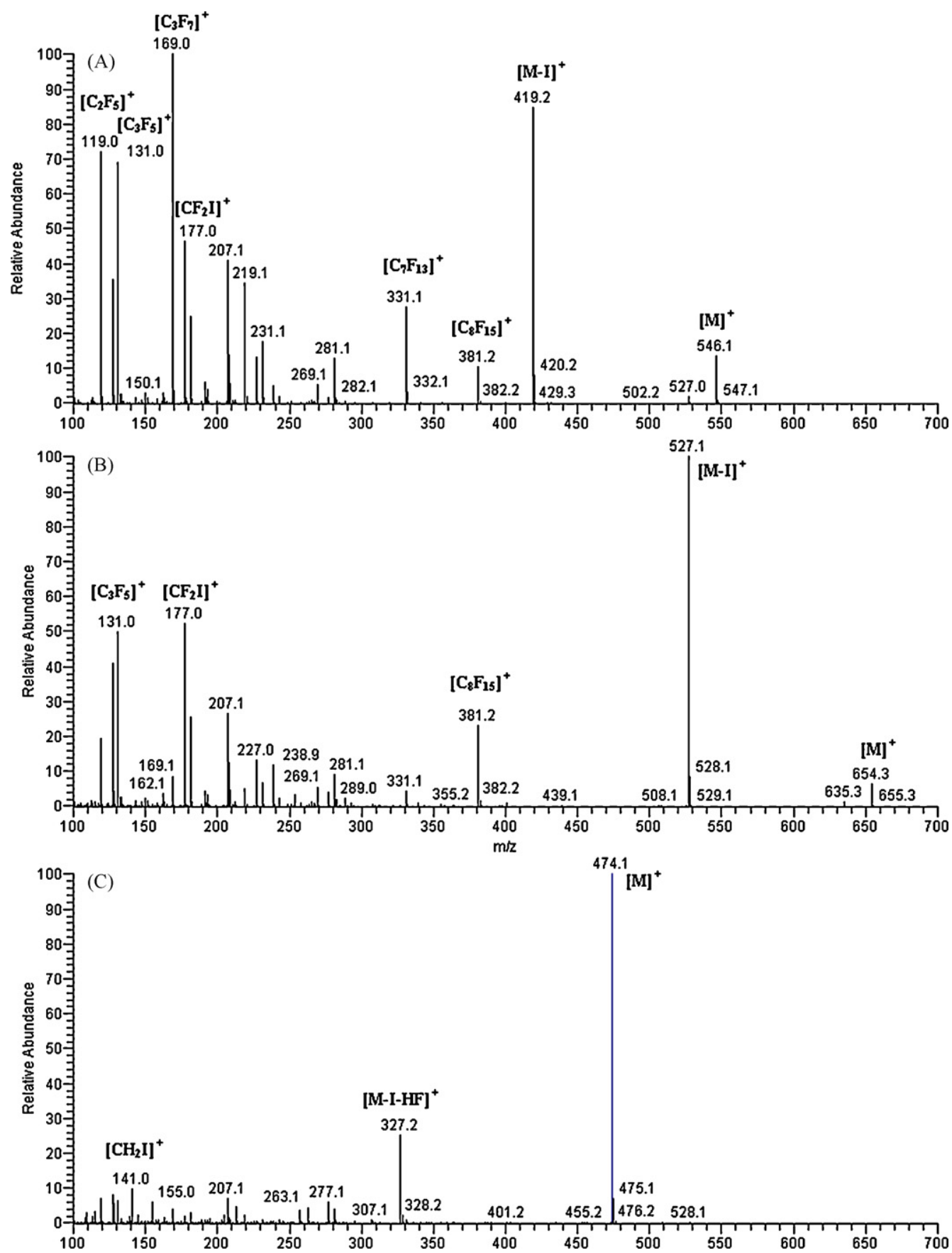

Fig. 1. Typical fragment ion spectra for the three groups of polyfluorinated iodine alkanes obtained ((A) PFOI, (B) PFODiI, (C) PFOHI) in EI scan mode at 45 eV.

the criteria that the ratio of the confirmation to the quantitative ions in real samples should be within $20 \%$ of that in the calibration standards and the few that exceeded the limitation were not quantified.

\subsection{Environmental sampling}

Air samples were collected at two sites in mid September, 2009 in Shandong Province, China. Three parallel ambient air samples were collected at downwind direction about $600 \mathrm{~m}$ away from a fluorochemical manufacturing site. Two control samples were collected in a remote area approximately $50 \mathrm{~km}$ south-west from the manufactory, with low population density and little industrial activities. Each cartridge was connected to a QC-1S portable mem- brane pump (50-500 mL/min, Beijing Labor Protection Science Research Institute, CN), which was positioned on a tripod $1.5 \mathrm{~m}$ above ground, $5 \mathrm{~m}$ apart from each other and distant from the roads. An additional back-up cartridge was added between each sampling tube and the pump to check whether breakthrough occurred during the sampling process. A flow rate of about $150 \mathrm{~mL} / \mathrm{min}$ was chosen and a total air volume of $3.75 \mathrm{~L}$ was sampled through the cartridges within $25 \mathrm{~min}$. Actual gas flow rate was calculated by recording the instant flow rate at the beginning and at the end of each sampling cycle and taking the average. Ambient temperature $\left(\sim 26.1^{\circ} \mathrm{C}\right)$, relative humidity ( 49\%) and atmospheric pressure (101.4 kPa) were measured for air sampling volume emendation. After the sampling ended, cartridges were well packed, stored inside a metal container with activated charcoal, placed in an ice-box and trans- 
ported back immediately. In total, 13 cartridges were taken to the laboratory.

\section{Result and discussion}

\subsection{Compound confirmation and fragmentation patterns}

Shown in Fig. 1 are the EI-HRMS mass spectrums of three reference standards ((A)-PFOI, (B)-PFODiI and (C)-PFOHI) in the full scan mode at $45 \mathrm{eV}$. In Fig. $1 \mathrm{~A}$, the molecular ion $(m / z=546)$ was observed with small intensity and the most abundant ion at $m / z=169$ corresponded to $\left[\mathrm{C}_{3} \mathrm{~F}_{7}\right]^{+}$. Abundant ions with small $\mathrm{m} / \mathrm{z}$ indicate low ionization energy of these mono-iodized perfluorinated alkanes which can be easily cleaved into small fragments. Loss of iodide ions were common among the homologues of the mono-iodized perfluorinated alkanes and high-abundance of $[\mathrm{M}-\mathrm{I}]^{+}$were formed. Fragment ions at $\mathrm{m} / z 381\left[\mathrm{C}_{8} \mathrm{~F}_{15}\right]^{+}$and 331 $\left[\mathrm{C}_{7} \mathrm{~F}_{13}\right]^{+}$corresponded to the sequential loss of $\left[\mathrm{F}_{2} \mathrm{I}\right]^{\bullet}$ and an additional $\mathrm{CF}_{2}$ backbone unit at the molecular end. $[\mathrm{M}-\mathrm{I}]^{+}$was used for quantification purpose and $[\mathrm{M}]^{+}$as confirmation ion for PFHxI and PFOI, while $\left[\mathrm{M}-\mathrm{I}-\mathrm{F}_{2}\right]^{+}$was used as the confirmation ion instead for PFDeI and PFDoI because of very low intensity of $[\mathrm{M}]^{+}$. Similar ionization mechanism was observed in diiodized perfluorinated alkanes (Fig. 1B), however only one iodine atom was effectively removed and $[\mathrm{M}-\mathrm{I}]^{+}$was formed as the most abundant ion. $[\mathrm{M}-\mathrm{I}]^{+}$ and $[\mathrm{M}]^{+}$were also used respectively as quantitative and confirmation ions except for PFODil (see above). For mono-iodized telomers, in Fig. $1 \mathrm{C}$, the molecular ion $[\mathrm{M}]^{+}$was the most abundant, while $[\mathrm{M}-\mathrm{I}]^{+}$ion seemed not to be present except for additional loss of a hydrogen and a fluorine atom to form $[\mathrm{M}-\mathrm{I}-\mathrm{HF}]^{+}$. Consequently, $[\mathrm{M}]^{+}$and $[\mathrm{M}-\mathrm{I}-\mathrm{HF}]^{+}$were chosen for analysis of all the monoiodized telomers. A chromatogram of a spiked cartridge in the MID analysis at $45 \mathrm{eV}$ is presented in Fig. 2. Additional scans were performed at $70 \mathrm{eV}$, and similar spectrums were obtained with slight decrease in abundance for higher $m / z$ characteristic ions. Therefore, the lower $45 \mathrm{eV}$ was set as the final ionization energy.

\subsection{Breakthrough experiment results}

Generally, breakthrough occurs with analyte mass loss greater than $5 \%$ on the sorbent [33]. However, when $1.4,2.5$ and $3.75 \mathrm{~L}$ pre-tested non-contaminated laboratory air was passed through the spiked multisorbent cartridges, no breakthrough was observed for the analytes $(<1 \%)$. For an air volume of $5 \mathrm{~L}$, mass loss of PFDoI occurred $(15.3 \pm 4.6 \%)$ while other analytes remained constant. When air sampling volume increased to $10 \mathrm{~L}$, breakthrough was also observed for PFODil (21.9 $\pm 2.7 \%)$. Breakthrough for analytes such as PFOI, PFDeI, PFHxHI, PFOHI and PFHxDiI occurred when $20 \mathrm{~L}$ ambient air was pumped into the cartridges. The breakthrough trend with increasing air volume indicated that the adsorption intensity of the multisorbent in use was dissimilar for the different PFIs. For perfluorinated iodine alkanes, the sorbents showed stronger affinity to analytes of less molecular weight while the adsorption of the sorbents was not very satisfactory for higher mass homologues. However, the situation was different for the polyfluorinated telomers iodides. The multisorbent showed much stronger interaction with the higher mass homologues and breakthrough only occurred for analytes with shorter carbon chains. Finally, 3.75 L was used as the safe sampling volume and applied for the ambient air sample collection.

\subsection{Flow rates/pre-purge optimization}

As mentioned in the EPA method TO-1 [35], the linear flow velocity of sorbent tube sampling should be in the range of
$50-500 \mathrm{~cm} / \mathrm{min}$. According to Eq. (1),

$Q_{\max }=\prod \times B \times r^{2}$.

$Q_{\max }$ : maximum flow rate in volume ( $\left.\mathrm{mL} / \mathrm{min}\right), B$ : linear flow velocity $(\mathrm{cm} / \mathrm{min}), r$ : inner semidiameter of sorbent tubes $(\mathrm{mm})$.

The maximum flow rate should be in the range of $16-161 \mathrm{~mL} / \mathrm{min}$. In our breakthrough experiments, $3.75 \mathrm{~L}$ ambient air was passed through the spiked cartridges and flow rates of $150,200,300 \mathrm{~mL} / \mathrm{min}$ were tested, each in triplicate. The results were normalized to the data obtained from $150 \mathrm{~mL} / \mathrm{min}$, and recoveries of PFIs at $200 \mathrm{~mL} / \mathrm{min}$ ranged from $92.0 \%$ to $98.9 \%$, and at $300 \mathrm{~mL} / \mathrm{min}$ the range was $75.5-96.5 \%$ with median value of $91.5 \%$. This also means that breakthrough might not occur even with infrequent high flow rate fluctuation of the sampling pumps. However, mass loss might be more pronounced during the thermal desorption procedure with pre-purge He gas flow of $50 \mathrm{~mL} / \mathrm{min}$ or higher. Compared with the results of spiked tubes without prepurge steps, recoveries for PFIs with prepurge steps were lower for PFOHI $(67.5 \pm 19.9 \%)$, PFOI $(73.9 \pm 2.3 \%)$, PFODiI $(82.1 \pm 15.5 \%)$, PFDeHI $(84.3 \pm 9.8 \%)$ with other analytes in the range of $86.5-96.8 \%$. In principle, analytes might partly be desorbed during purging procedures even though the steps were taken under ambient temperature. Besides, some parts of the cartridges, such as the inlet side near the heating component of the equipment, could be slightly heated which might lead to significant reduction of the SSV and noticeable mass desorption. Thus, a more gentle gas flow of $15 \mathrm{~mL} / \mathrm{min}$ was chosen for the split purge procedures where analyte recoveries were in the range of $84.4-108 \%$.

\subsection{Blank and blank correction}

The TIC chromatogram of lot blank tubes is shown in Fig. S1. Most of the analytes were not detectable in lot tubes except for PFDoHI (level around the LOQ) and small amount of the internal standard. The residues were probably from the graphitized carbon cold trap since similar situation repeated when pre-cleaned empty stainless tube without sorbents was desorbed. Background was subtracted for other blank measurements and an additional desorption cycle with $1 \mu \mathrm{L}$ acetone helped eliminating the residues. No PFIs were found in laboratory blanks, while a small amount of PFDoHI was detected in one field blank (5.3 pg, approximately $13 \%$ of the concentration in the corresponding sampling tube). It indicated that diffusive enrichment of PFIs might occur even under ambient air conditions, and the sampling cartridges should be well packed to avoid field contamination. However, no analytes detected in our trip blanks ensured the veracity of the sampling protocol. As most of the PFIs were below detection limit or very low (concentration $<1 \%$ of the samples and the internal standard added), no subtraction was performed for sample quantification except for PFDoHI.

\subsection{Method performance}

To evaluate the performance of this optimized TD-GC-HRMS approach for the selected compounds, linearity, sensitivity, accuracy and repeatability were taken into account. Results from validation of the analytical method are summarized in Table 3. Instrument response factors for each analyte were calculated by analysis of seven calibration levels of standard mixtures, each in triplicate. The average ratios of the integrated area of analytes related to that of the IS were plotted against the target analyte concentrations. Least squared regression analysis showed good linearity $\left(R^{2}>0.9912\right)$ within the range of $10-1000 \mathrm{pg}$ for all of the compounds of interest. 


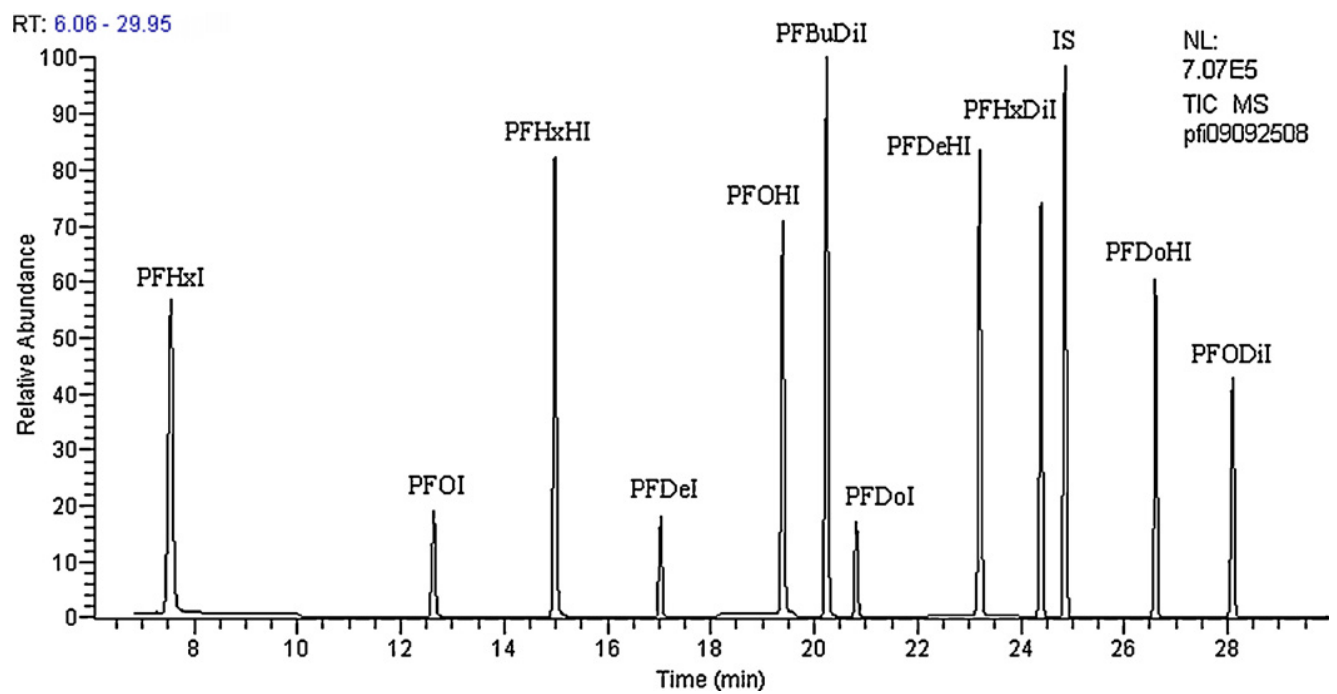

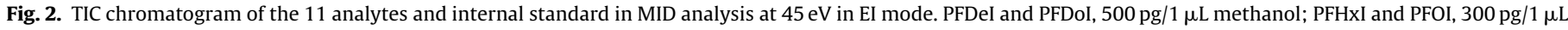
methanol; others $200 \mathrm{pg} / 1 \mu \mathrm{L}$ methanol.

Table 3

Validation data and performance of the TD-GC/HRMS method.

\begin{tabular}{|c|c|c|c|c|c|c|c|}
\hline & \multicolumn{2}{|c|}{ Limit of detection ${ }^{\mathrm{a}}$} & \multirow[t]{2}{*}{ Linearity $^{\mathrm{b}} / R^{2}$} & \multicolumn{2}{|c|}{ Accuracy (recovery, \%) } & \multicolumn{2}{|c|}{ Repeatability (RSD, \%) } \\
\hline & EDL (pg) & $\operatorname{MDL}(\mathrm{pg} / \mathrm{L})$ & & Travel spike & Tube-to-tube $^{\mathrm{d}}$ & $10 \mathrm{pg}$ level & 200 pg level \\
\hline PFHxI & 2.2 & 1.2 & 0.9912 & 116 & 2.3 & 6.2 & 3.6 \\
\hline PFOI & 0.9 & 0.91 & 0.9958 & 111 & 4.2 & 22 & 7.2 \\
\hline PFDeI & 0.3 & 0.86 & 0.9967 & 99 & 7.9 & 29 & 7.3 \\
\hline PFDoI & 0.3 & 0.38 & 0.9924 & 89 & 9.7 & 7.5 & 2.5 \\
\hline PFHxHI & 0.2 & 0.27 & 0.9929 & 105 & 2.6 & 36 & 2.9 \\
\hline PFOHI & 0.3 & 0.14 & 0.9956 & 90 & 1.2 & 7.7 & 4.2 \\
\hline PFDeHI & 0.1 & 0.09 & 0.9990 & 101 & 4.7 & 11 & 3.0 \\
\hline PFDoHI & 0.1 & 0.04 & 0.9941 & 107 & 4.7 & 12 & 3.6 \\
\hline PFBuDiI & 0.7 & 0.38 & 0.9914 & 108 & 3.7 & 15 & 3.5 \\
\hline PFHxDiI & 0.4 & 1.0 & 0.9940 & 97 & 3.0 & 17 & 4.5 \\
\hline PFODiI & 0.5 & 0.32 & 0.9992 & 83 & 4.8 & 17 & 2.1 \\
\hline
\end{tabular}

a EDL, equipment detection limit, calculated by signal/noise $>3$ in the chromatography; MDL, method detection limit, five replicate injections of low level of analytes in $1 \mu \mathrm{L}$ methanol spiked in cartridges.

b Seven-point calibration (10-1000 pg, each in triplicate).

c $500 \mathrm{pg}$ level for each of the analyte.

d Standard derivations of analytes concentrations in parallel tubes calculated using the data of travel spikes.

e Same data used from linearity and range.

In view of the interference of real samples in MDL determination, low concentrations of PFIs were spiked in sorbent cartridges pre-inbreathed of $3.75 \mathrm{~L}$ non-contaminated laboratory air. PFOHI, PFDeHI and PFDoHI levels were within a concentration factor of 10 of the final MDL values, the rest within a factor of 5. Five replicate injections were necessary for the determination and the method detection limit was thus defined similarly as mentioned elsewhere [35]:

$\mathrm{MDL}=A+3.4 S$

where $A$ is the intercept calculated from the least squared regression analysis as mentioned in linearity measurement section, $S$ is the standard deviation of the five replicate determinations, 3.4 is the $t$-test distribution coefficient, $n=5,0.01$ level. MDL improved with increased molecular weight for all the three PFI groups of congeners, indicating less baseline interference and higher $\mathrm{S} / \mathrm{N}$ obtained when higher quantification ions were monitored.

The travel spike recoveries were within the range of $82.9-116 \%$ for the analytes and recoveries of laboratory check standards were all close to $100 \%$. Tube-to-tube variations of the sorbent cartridges were also measured using the data from triplicate travel spikes. Relative standard derivations (RSD) ranged from 1.2\% (PFOHI) to 9.7\% (PFDoI), indicated good reliability since it also measures the
Table 4

Optimized parameters of the TD-GC-HRMS system for the analysis of ambient air samples.

\begin{tabular}{ll}
\hline Ambient air sampling & \\
Safe sampling volume & $3.75 \mathrm{~L}$ \\
Sampling flow rate & $150 \mathrm{~mL} / \mathrm{min}$ \\
Thermal desorption procedure & \\
Makeup gas flow in liquid standard spike & $30 \mathrm{~mL} / \mathrm{min}$, He gas \\
Prepurge time & $1 \mathrm{~min}$ \\
Prepurge temperature & Ambient temp. \\
Prepurge gas flow & $15 \mathrm{~mL} / \mathrm{min}$, He gas \\
Tube desorption temperature & $280^{\circ} \mathrm{C}$ \\
Tube desorption time & $8 \mathrm{~min}$ \\
Tube desorption gas flow & $30 \mathrm{~mL} / \mathrm{min}$, He gas \\
Trap temperature & $-10^{\circ} \mathrm{C}$ \\
Pre-trap fire purge time & $1 \mathrm{~min}$ \\
Pre-trap fire purge gas flow & $15 \mathrm{~mL} / \mathrm{min}$, He gas \\
Trap desorption temperature & $300^{\circ} \mathrm{C}$ \\
Trap desorption time & $3 \mathrm{~min}$ \\
GC-HRMS instrument parameters & \\
Ionization mode & $\mathrm{EI} \mathrm{Positive}$ \\
Electron energy & $45 \mathrm{eV}$ \\
Source temperature & $250^{\circ} \mathrm{C}$ \\
Instrument reference & $\mathrm{FC} 43$ \\
Resolution & $\sim 5000(5 \%$ valley $)$ \\
\hline
\end{tabular}




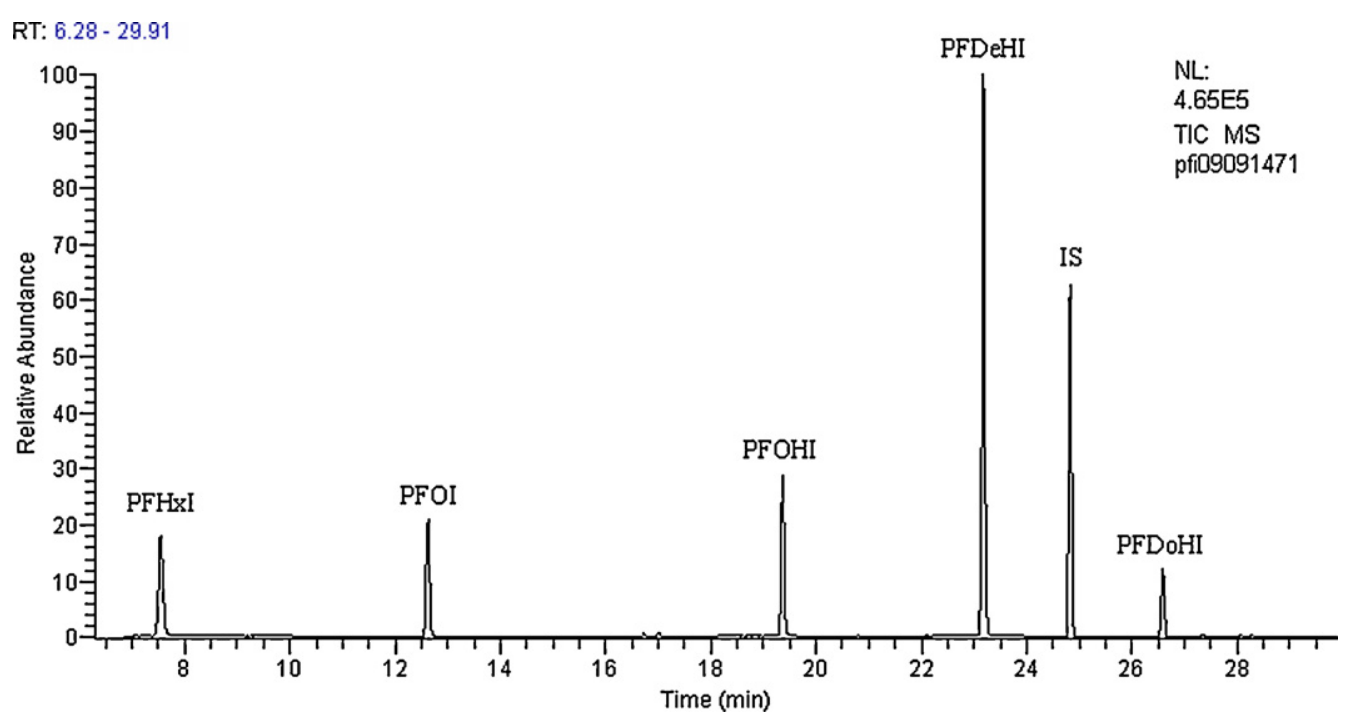

Fig. 3. TIC chromatogram of an ambient air sample in MID analysis at $45 \mathrm{eV}$ EI mode. Five PFIs were detected to be present in the environment.

effect of possible mass loss during sample transportation in addition to the tube-to-tube reproducibility. Thermal stability of the analytes was measured by optimizing the injector temperature in liquid injection mode and thermal desorption temperature in sorbent desorption mode. No obvious degradation occurred in the inject port as no significant difference $(p>0.05)$ was observed when the injection temperature was set to $180,200,220,250$ and $280^{\circ} \mathrm{C}$, except that MS response decreased at $180^{\circ} \mathrm{C}$ (from $74.2 \%$ (PFDoHI) to $84.7 \%$ (PFBuDiI)) probably caused by incomplete analyte vaporization. No significant difference was further observed when desorption temperature was set as 200, 250 and $280^{\circ} \mathrm{C}$. Finally, desorption temperature in the "trap/quick release" desorption strategy was set at $280^{\circ} \mathrm{C}$ and 8 min was sufficient for complete desorption, as the analytes were almost undetectable or at very low residue concentrations $(<1 \%)$ when cartridges were reanalyzed for another desorption cycle. However, when the transfer line temperature was set as high as $200^{\circ} \mathrm{C}$, compared with that of $140^{\circ} \mathrm{C}$, recoveries of some analytes decreased, such as for PFBuDiI $(77.5 \pm 10.2 \%)$ and PFODiI $(82.3 \pm 12.4 \%)$. One possible explanation was that thermal degradation might be possible as pressure and carrier gas flow was low in the transfer line and analyte remained at elevated temperature for a relatively longer time. Lower temperature $\left(140^{\circ} \mathrm{C}\right)$ in the transfer line might be appropriate for more accurate quantification. Besides, the transfer line temperature was several degrees lower than that of the sorbent desorption procedure, which could help reducing vapor diffusing in the transfer line and thus enhance peak shapes.

Ranges of relative standard deviations of the compounds at 10 and $200 \mathrm{pg}$ levels were used as a measurement for the method repeatability determination, using triplicate data from regression analysis. As expected, good unity were obtained at $200 \mathrm{pg}$ spike level for all the analytes with RSD in the range of 2.1\% (PFODiI) $-7.3 \%$ (PFDoHI), while repeatability decreased with RSD from 6.2\% (PFHxI) to $36 \%$ (PFHxHI) at $10 \mathrm{pg}$ level as concentration of many analytes were close to its MDL.

\subsection{Application to ambient air}

The TD-GC-HRMS method was applied to determine airborne concentrations of the three groups of polyfluorinated iodine alkanes in ambient air samples as shown in Table 4. The results were subtracted for blank residues but travel spike recoveries were not taken into account. Fig. 3 shows the TIC chromatogram of the collected air sample, in which two mono-iodized perfluorinated alkanes and three mono-iodized telomers were detected in all of the three simultaneously collected samples. Compared with that of PFDoHI (10.8 pg/L) and PFOHI (18.8 pg/L), relatively higher concentrations were observed for PFOI (85.0 pg/L), PFDeHI $(50.4 \mathrm{pg} / \mathrm{L})$ and PFHxI $(48.2 \mathrm{pg} / \mathrm{L})$, with RSD of the detected analytes in the range of $16.6 \%$ (PFDoHI) to $34.6 \%$ (PFHxI) for the three parallel samples. This might be caused by spatial concentration variation of these PFI analytes in the sampling site and difference in actual air volume passing through each sampling tube. To our knowledge, this is the first time that this group of chemicals has been reported to be present in the ambient environment. The analytes in the backup tubes collected at the sampling site were under the detection limit or very low (<1.5\%), which confirmed that no obvious breakthrough occurred during the ambient air sampling. None of the PFIs were detected in the cartridges collected at the control site, further implicating a point source emission from the factory. Moreover, none of the diiodized perfluorinated alkanes were detectable in any of the sampling cartridges, field blanks and back-up tubes. Although the sampling period was not extensive, it might nevertheless imply that diiodized perfluorinated alkanes were at very low concentrations in the investigated regions or might not be important by-products of the telomerization process, as was mentioned in the literature elsewhere [13]. Also as can be seen from Fig. 3, few interference peaks was found in the real sample analysis. However, when low resolution MS was used as the detector in our preliminary work, additional smaller fragment ions (typically $m / z<300$ ) had to be chosen and monitored for each of the analyte to meet the strict compound positive identification criteria of the EU regulation [36]. The analyte confirmation was strongly interfered by background ions such as $m / z=219$, as shown in Fig. S2, which are probably fragments of other small-chain volatile fluorides. Thus, by measuring characteristic ions of high molecular weight used in our TD-GC-HRMS method would prevent most background interferences while still ensuring positive identification of the analytes of interest.

\section{Conclusions}

For the first time, a TD-GC-HRMS method has been developed for the determination of iodized fluorochemical telomerization products in ambient air. It allows for simultaneous analysis of eleven polyfluorinated iodine alkanes with wide range of esti- 
mated volatilities (0.07-20.4 Torr). Important parameters such as those affecting the sorbent SSV and thermal desorption efficiency were investigated and discussed. Two mono-iodized perfluorinated alkanes and three mono-iodized telomers were reported, for the first time, to be present in the environment $(10.8-85.0 \mathrm{pg} / \mathrm{L})$. This method could be extended to more detailed studies to evaluate the presence and spatial concentrations of these chemicals at large geographical scale, investigate probable photo-degradation mechanisms and atmospheric lifetimes which influent the persistence and long-range transport abilities of these chemicals. Their transformation patterns in the real environment are also important as possible conversions to other well-known polyfluorinated compounds which might lead to additional input to the global PFCs burden.

\section{Acknowledgments}

This work was jointly supported by the National Basic Research Program of China (2009CB421605) and the National Natural Science Foundation $(20677068,20897011)$.

\section{Appendix A. Supplementary data}

Supplementary data associated with this article can be found, in the online version, at doi:10.1016/j.chroma.2010.04.051.

\section{References}

[1] E. Kissa, Fluorinated Surfactants and Repellants, 2nd ed., Marcel Dekker, New York, 2001.

[2] K. Prevedouros, I.T. Cousins, R.C. Buck, S.H. Korzeniowski, Environ. Sci. Technol. $40(2006) 32$.

[3] UNEP, SC-4/17: Listing of perfluorooctane sulfonic acid, its salts and perfluorooctane sulfonyl fluoride, COP-4, Stockholm Convention on Persistent Organic Pollutants, UNEP, 2009.

[4] OECD, Hazard Assessment of Perfluorooctane Sulfonate (PFOS) and its Salts, ENV/JM/RD (2002)17/FINAL, Organization for Economic Co-operation and Development, Pairs, 2002.

[5] K. Kannan, S. Corsolini, J. Falandysz, G. Fillmann, K.S. Kumar, B.G. Loganathan, M.A. Mohd, J. Olivero, N.V.Wouwe, J.H. Yang, K.M. Aldous, Environ. Sci. Technol. 38 (2004) 4489.

[6] A. Kärrman, I. Ericson, B.V. Bavel, P.O. Darnerud, M. Aune, A. Glynn, S. Lignell, G. Lindström, Environ. Health Perspect. 115 (2007) 226.

[7] K. Kannan, S. Corsolini, J. Falandysz, G. Oehme, S. Focardi, J.P. Giesy, Environ. Sci. Technol. 36 (2002) 3210.

[8] G.T. Tomy, W. Budakowski, T. Halldorson, P.A. Helm, G.A. Stern, K. Friesen, K. Pepper, S.A. Tittlemier, A.T. Fisk, Environ. Sci. Technol. 38 (2004) 6475.
[9] A. Jahnke, U. Berger, R. Ebinghaus, C. Temme, Environ. Sci. Technol. 41 (2007) 3055.

[10] N.L. Stock, V.I. Furdui, D.C.G. Muir, S.A. Mabury, Environ. Sci. Technol. 41 (2007) 3529.

[11] M.J. Dinglasan, Y. Ye, E.A. Edwards, S.A. Mabury, Environ. Sci. Technol. 38 (2004) 2857.

[12] N. Wang, B. Szostek, R.C. Buck, P.W. Folsom, L.M. Sulecki, J.T. Gannon, Chemosphere 75 (2009) 1089.

[13] H. Lehmler, Chemosphere 58 (2005) 1471.

[14] P.H. Howard, W. Meylan, EPA Contract No. EP-W-04-019 SRC FA488. U.S. Environmental Protection Agency, Washington, DC, 2009.

[15] OECD, The 2004 OECD List of High Production Volume Chemicals. Environment Directorate, Organization for Economic Co-operation and Development, Pairs, 2004.

[16] T.N. Brown, F. Wania, Environ. Sci. Technol. 42 (2008) 5202.

[17] C.J. Young, M.D. Hurley, T.J. Wallington, S.A. Mabury, J. Phys. Chem. A 112 (2008) 13542.

[18] T. Umemoto, Chem. Rev. 96 (1996) 1757.

[19] J.W. Martin, D.C. Muir, C.A. Moody, D.A. Ellis, W.C. Kwan, K.R. Solomon, S.A. Mabury, Anal. Chem. 74 (2002) 584.

[20] M. Shoeib, T. Harner, P. Vlahos, Environ. Sci. Technol. 40 (2006) 7577.

[21] B. Boulanger, A.M. Peck, J.L. Schnoor, K.C. Hornbuckle, Environ. Sci. Technol. 39 (2005) 74.

[22] A.M. Piekarz, T. Primbs, J.A. Field, D.F. Barofsky, S. Simonich, Environ. Sci. Technol. 41 (2007) 8248.

[23] M. Shoeib, T. Harner, S.C. Lee, D. Lane, J. Zhu, Anal. Chem. 80 (2008) 675.

[24] U.S. EPA. Exposure Assessment Tools and Models, Estimation Program Interface (EPI) Suite, V 3.20, U.S. Environmental Protection Agency, Exposure Assessment Branch, Washington, DC, 2007.

[25] B.S. Larsen, P. Stchur, B. Szostek, S.F. Bachmura, R.C. Rowand, K.B. Pricket, S.H. Korzeniowski, R.C. Buck, J. Chromatogr. A 1110 (2006) 117.

[26] U.S. EPA. Method 5041A: Analysis For Desorption of Sorbent Cartridges From Volatile Organic Sampling Train (VOST), U.S. Environmental Protection Agency, Washington, DC, 1996.

[27] J.F. Pankow, W. Luo, L.M. Isabelle, D.A. Bender, R.J. Baker, Anal. Chem. 70 (1998) 5213.

[28] D. Waterman, B. Horsfield, F. Leistner, K. Hall, S. Smith, Anal. Chem. 72 (2000) 3563.

[29] M.E. Sigman, C. Ma, R.H. Ilgner, Anal. Chem. 73 (2001) 792.

[30] K.M. Cooke, P.G. Simmonds, G. Nickless, A.P.W. Makepeace, Anal. Chem. 73 (2001) 4295.

[31] M.R. Ras, F. Borrull, R.M. Marcé, Trends Anal. Chem. 28 (2009) 347.

[32] Markes International, Thermal Desorption Accessories and Consumables, Markes International Corporation, Llantrisant, U.K., 2009.

[33] U.S. EPA. Compendium Method TO-17: Determination of Volatile Organic Compounds in Ambient Air Using Active Sampling Onto Sorbent Tubes, U.S. Environmental Protection Agency, Washington, DC, 1999.

[34] E. Hoh, L.Y. Zhu, R.A. Hites, Environ. Sci. Technol. 40 (2006) 1184.

[35] U.S. EPA. Compendium Method TO-1: Method for The Determination of Volatile Organic Compounds in Ambient Air Using Tenax ${ }^{\circledR}$ Adsorption and Gas Chromatography/Mass Spectrometry, U.S. Environmental Protection Agency, Washington, DC, 1984.

[36] EU Commission Decision 2002/657/EC, Official Journal of the European Communities, 2002, L 221/8, 17.8.2002. 